\title{
Hutcheson sobre a importância de ser desinteressado. Um encômio a Shaftesbury?
}

\author{
Laurent Jaffro
}

Paris I Panthéon-Sorbonne

Tradução: Eveline Campos Hauck 

A Investigação quanto a Origem de nossas Ideias de Beleza e Virtude de Hutcheson pretende ser, entre outras coisas, (estou simplesmente parafraseando seu subtítulo) uma "explicação" e uma "defesa" dos "princípios" de Shaftesbury contra Mandeville. Meu intuito neste artigo é identificar quais são aqueles princípios de Shaftesbury que Hutcheson explica e defende. Para entregar o ouro: minha visão é a de que esses princípios são simplesmente (ou ao menos principalmente) o seguinte: primeiramente, que os motivos do juízo moral, as fontes da aprovação ou desaprovação moral, não podem ser encontrados no interesse próprio, mas antes em um sentido desinteressado de certo e errado. Em segundo lugar, que razões morais para agir, isto é, as fontes de motivação moral, não podem ser reduzidas ao interesse próprio. Em uma palavra, o desinteresse é uma característica básica tanto do juízo moral quanto da motivação moral. Hutcheson concorda com Shaftesbury principalmente nesse ponto.

Isso significa que há muitos princípios em Shaftesbury dos quais Hutcheson não se aproxima absolutamente. Concentrar-me-ei em dois deles: 1. Que sentido moral é conhecimento moral. 2. Que há uma identidade, ou ao menos uma forte conexão interna, entre beleza moral e beleza natural verdadeira. Para Hutcheson, primeiramente, como mostrarei, sentido moral não é conhecimento moral, mas antes sentimento moral de um modo que contrasta sentimento com conhecimento; em segundo lugar, se colocarmos de lado o fato de que ele denomina "beleza relativa" em oposição a "beleza absoluta", não há conexão interna entre moralidade e beleza e, em nenhuma circunstância, há qualquer identidade entre beleza moral e beleza natural, ainda que haja, obviamente, uma analogia entre os processos psicológicos envolvidos na percepção do belo e aqueles envolvidos na percepção do bom.

Minha proposição será de que Hutcheson concorda com Shaftesbury na superfície, na medida em que concorda com a importância, em questões morais e estéticas, do desinteresse. 
Muitos comentadores enfatizaram recentemente duas diferenças entre Shaftesbury e Hutcheson. 1. O sentido moral em Shaftesbury não é apenas (para usar expressões de Thomas Reid) um princípio de especulação, mas também um princípio de ação, ao passo que para Hutcheson o sentido moral é um sentido de especulação, o princípio de ação deve ser antes encontrado em disposições tais como a benevolência (a distinção entre "predileção" e "aprovação" será claramente formulada nas Ilustrações, embora já esteja implícita na Investigação). 2. Hutcheson segue a rejeição empirista de Locke do inatismo, enquanto Shaftesbury insiste na forma platônica de que noções morais são "conaturais" ao desenvolvimento da alma. Aqui a diferença é entre, por um lado, um seguidor dos platonistas de Cambridge e, por outro, um discípulo de John Locke - na verdade, não um discípulo da explicação de Locke sobre moralidade, mas antes de sua epistemologia e psicologia. Creio que o quadro esteja correto, ainda que aquelas duas diferenças não sejam as únicas.

Meu ponto é que se colocarmos de lado o desacordo quanto ao inatismo e se focarmos no juízo moral, isto é, no sentido moral enquanto um princípio de especulação simplesmente (deixando de lado a questão de se esse princípio de especulação é ou não é também um princípio de ação), em uma palavra, se nos concentrarmos naquilo que parece ser comum a Shaftesbury e a Hutcheson, ou seja, a proposição de que somos capazes de uma apreensão desinteressada e imediata de qualidades morais e estéticas, restará uma dúvida significativa se eles querem dizer a mesma coisa quando ambos afirmam que o desinteresse é uma característica básica do juízo moral. Não irei discutir o conceito de "desinteresse" (juízo moral é desinteressado de modo que não pode ser reduzido a uma expressão de interesse próprio). Uma de minhas proposições neste trabalho não é a de que Hutcheson e Shaftesbury têm conceitos diferentes de desinteresse (embora acredite que haja realmente muitas diferenças entre suas concepções), mas antes a de que mesmo se aceitarmos a opinião de que 
eles têm em linhas gerais a mesma concepção de desinteresse, seus argumentos para a importância do desinteresse não são baseados nas mesmas premissas.

\section{Sentido: prazer ou conhecimento?}

Comecemos com a definição de sentido moral de Hutcheson. O sentido moral (e o sentido de beleza também) é um poder de satisfazer-se por certas qualidades, não um poder de conhecer certas qualidades. Há uma conexão direta entre o sentido moral e o prazer, bem como entre o sentido de beleza e o prazer, uma vez que Hutcheson caracteriza os sentidos como "determinações para se satisfazer com quaisquer formas ou ideias que ocorrem a nossa observação" '. Quando nosso sentido moral percebe uma qualidade moral que mereça ser aprovada, satisfazemo-nos por causa daquela qualidade. É muito importante notar que a relação entre o prazer e a qualidade é causal de modo que o prazer é excitado pela qualidade. Se perguntarmos se aquela relação é apenas causal, aproximamos de uma dificuldade. Pois é claro que a relação entre o prazer e a qualidade não envolve apenas a causalidade entre a qualidade e o prazer, mas também uma "apreensão" da qualidade através do prazer; de modo que o prazer que sentimos quando consideramos as formas belas (ou o prazer diferente que sentimos quando consideramos boas ações) não é apenas efeito da qualidade, mas também um meio de apreendê-la.

Entretanto, ao mesmo tempo, Hutcheson reafirma convictamente que o prazer envolvido aqui não é de modo algum condicionado pelo conhecimento da qualidade. Hutcheson frequentemente contrasta conhecimento com prazer, como fica evidente nesta passagem do primeiro tratado: "muitas das nossas percepções sensíveis são imediatamente agradáveis, e muitas, dolorosas,

1 Hutcheson, "An Inquiry into the Original of our Ideas of Beauty and Virtue in two Treatises", editado por Wolfgang Leidhold, Indianopolis: Liberty Fund, 2004, prefácio, p. 8. 
e isso sem qualquer conhecimento da causa desse prazer ou dor, ou de como os objetos provocam ou são a ocasião disso" (p. zo21)". Algumas páginas depois, ele insiste que o sentido do belo "é com justiça chamado de sentido, por causa de sua afinidade com outros sentidos nela [na percepção], de tal modo que o prazer não surge de qualquer conhecimento de princípios, proporções, causas, ou da utilidade do objeto, mas nos toca primeiramente com a ideia de beleza; nem o mais acurado conhecimento aumenta esse prazer de beleza, entretanto, pode superadicionar um prazer racional distinto de perspectivas de vantagem, ou do aumento de conhecimento" (Ibid., p. 25). O prazer é sentido tão logo a ideia é causada pela qualidade. O efeito é tão imediato que não sobra lugar para qualquer raciocínio, pensamento sobre as consequências ou cálculo de interesses. O melhor argumento a favor do desinteresse na aprovação moral e estética é o do imediatismo do prazer. Retornarei a esse ponto em um instante, uma vez que aqui Hutcheson se afasta de Shaftesbury.

Para ser justo, devo enfatizar que quando Hutcheson contrasta prazer com conhecimento, ele frequentemente tem em mente conhecimento a partir dos sentidos externos. Por exemplo, quando diz que uma pessoa "de um bom gosto irá se deleitar" com o prazer de beleza "imediatamente sem conhecimento", ele não quer dizer que o próprio prazer seja um tipo de conhecimento, mas que ele não depende do conhecimento "daquilo que os sentidos externos descobrem" (Ibid., p. 24). De modo que, estritamente falando, a maneira de Hutcheson de contrastar prazer com conhecimento não implica necessariamente que conhecimento moral ou conhecimento estético não possa existir. Quando sentimos prazer estético, sentimos que algo é belo e, dessa forma, apreendemos uma qualidade bela através daquele prazer. Vamos tentar seguir essa linha de argumentação. Aqui está um exemplo do segundo tratado, seção 2: "Amor à complacência, estima ou amizade parece ser desinteressado à primeira vista, e da mesma forma o ódio à displicência ou desgosto, e são inteiramente excitados 
por qualidades morais, boas ou más, apreendidas como partes dos objetos; a própria estrutura de nossa natureza nos determina quais qualidades amar ou odiar, aprovar ou desaprovar, de acordo com o sentido moral acima explicado" (Ibid., p. 103). Poucas páginas depois, Hutcheson acrescenta: "O mesmo argumento que prova que o amor à estima é desinteressado, provará também que essa reverência honrosa o é; pois ele claramente surge da apreensão de qualidades amáveis na pessoa, e do amor a ela, que suscita uma aversão a ofendê-la" (Ibid., pp. 106-107). Parece que aqui temos motivos para acreditar que o prazer hutchesoniano não é apenas o efeito de uma disposição causal secreta, mas também um meio cognitivo de apreensão de qualidade causal.

Em outra parte, no primeiro tratado, quando lida com a beleza absoluta, Hutcheson menciona que crianças deleitam-se com figuras ou formas muito simples, "onde a variedade não é tão vasta para sua compreensão” (Ibid., p. 30). No caso da beleza absoluta, que é o efeito da qualidade caracterizada por Hutcheson como "uniformidade em meio a variedade", parece que temos bons motivos para reafirmar que prazer é um modo de apreender ou compreender, ou (por que não?) conhecer a qualidade que causa prazer, uma vez que naquele caso "as ideias de beleza e harmonia são excitadas por nossa percepção de alguma qualidade primária e estão relacionadas a figura e tempo, talvez elas possam ter realmente uma semelhança mais próxima com os objetos do que essas sensações, que não se parecem tanto com imagens de objetos quanto modificações da mente que percebe" (Ibid., p. 27).

Porém, nossa tentativa de assimilar prazer estético a conhecimento, ou pelo menos "compreensão", para abruptamente, uma vez que a conclusão da seção 2 deixa claro que "em todos esses exemplos de beleza... o prazer é comunicado a aqueles que nunca refletiram sobre esse fundamento geral; e que tudo que foi alegado aqui é "que a sensação prazerosa surge apenas de objetos em que há uniformidade em meio a variedade:" podemos ter a sensação sem conhecer qual é sua causa; igualmente, o paladar 
do homem pode sugerir ideias de doçura, acidez, amargor, embora ele seja ignorante das formas dos pequenos corpos, ou dos seus movimentos, que excitam nele essas percepções" (Ibid., p. 35). Hutcheson diz que podemos ter o prazer sem o conhecimento. Essa é uma afirmação mais forte do que a que já encontramos (ou seja, que o prazer estético não se vale do conhecimento que adquirimos através de nossos sentidos externos), uma vez que não há dúvida de que aqui Hutcheson quer dizer que prazer não é conhecimento, isto é, que o sentido interno não envolve o conhecimento das qualidades causais. Também é óbvio que aqui a palavra "forma" tem o sentido corpuscular, não o platônico. Uma forma é uma configuração das pequenas partes de corpos.

Diga-se de passagem, eu não seguiria Wolfgang Leidhold, em sua introdução à sua edição da Investigação (Ibid., p. xi), em que defende que, quando Hutcheson caracteriza a qualidade específica que percebemos em percepção estética como uma "forma", ele tem em mente o conceito de forma shaftesburiano, isto é, platônico. Cito: "Forma é a versão latina do termo grego platônico idea. A beleza é, então, a "forma externa" de coisas, refletindo a "forma interna" de algum "poder formador". Assim, Hutcheson define a beleza como uma "forma" ou como uma "figura... na qual há uniformidade em meio a variedade”. Ao contrário, reafirmo que a forma hutchesoniana é mais uma qualidade lockeana do que uma forma platônica. Longe de ser contemplada, como um objeto de conhecimento, a qualidade opera como uma causa do prazer através do qual é apreendido, a apreensão não sendo nada mais que prazer.

O modo no qual Hutcheson contrasta prazer com conhecimento é uma pista para se entender seu conceito de desinteresse. $\mathrm{O}$ argumento de Hutcheson para a natureza desinteressada do juízo moral ou estético é o seguinte: sentimos prazer na experiência de beleza (ou na contemplação de boas ações), tão imediatamente que não há qualquer espaço para reflexão ou conhecimento. Se tivéssemos tempo para reflexão ou conhecimento, talvez entendería- 
mos o uso dos objetos com os quais imediatamente nos deleitamos. Por isso, não sentimos prazer estético ou prazer moral por causa de uma experiência ou juízo desinteressado, nem por causa da natureza daquilo que é experimentado ou julgado. É o contrário. Juízo estético e juízo moral são desinteressados porque são imediatos, ou, mais precisamente, porque consistem em sentir um prazer que surge imediatamente. Cito da seção 3 da primeira investigação, "Da beleza de teoremas": "Por mais que o conhecimento amplie a mente e nos torne mais capazes de opiniões e projetos amplos em algum tipo de atividade, de que a vantagem pode ocorrer a nós; ainda assim, deixemos que, cada estudante, em seu íntimo, determine se não muitas vezes sentiu esse prazer sem nenhuma perspectiva de vantagem a partir do descobrimento de seu teorema. Tudo que pode ser inferido, consequentemente, é somente isso: que tanto como em nossos sentidos externos, também em nossos internos, as sensações prazerosas geralmente surgem daqueles objetos que a calma razão recomendaria, uma vez que tenhamos entendido seu uso, e que possivelmente envolveram nossas buscas a partir de interesse próprio” (Ibid., p. 40). Nessa passagem, conhecimento é conhecimento do "uso" ou da "vantagem". Por que isso? Porque conhecer algo, ou refletir sobre algo, ou raciocinar sobre algo, consiste em considerar as consequências para além de nossa experiência presente. Aqui o termo "conhecimento" adquiriu um significado muito estranho, distante do significado que tem em John Locke e ainda mais distante daquele da tradição platônica, uma vez que parece que para Hutcheson "conhecimento intuitivo" ou "conhecimento imediato" seria uma contradição. É importante notar também que o desinteresse não é nem uma condição de juízo moral, nem estético, tampouco é imposto pela natureza do objeto. Juízo moral ou estético é desinteressado de modo que, quando sentimos esse tipo de prazer, nós não pensamos no nosso próprio interesse privado. Isso não significa que nosso interesse não possa ter contado naquela questão, mas somente que ele não é um objeto intencional para o juízo moral e estético. 
O argumento hutchesoniano para o desinteresse é um argumento a partir da imediatez - da imediatez do prazer. Cito outra passagem, da seção 1 no primeiro tratado: “'Alguns objetos são imediatamente ocasiões desse prazer de beleza, e... temos sentidos próprios para sua percepção e... é distinto da alegria que surge do amor-próprio mediante a perspectiva de vantagem. ' De fato não vemos com frequência a conveniência e o uso negligenciados para se alcançar a beleza, sem qualquer outra perspectiva de vantagem na forma bela do que o que sugere as ideias agradáveis de beleza?" (Ibid., p. 25). Acho que esse argumento é muito diferente do argumento para o desinteresse que encontramos em Shaftesbury.

Para Shaftesbury, juízo moral (e também o juízo de beleza) é desinteressado não por causa da imediatez do prazer, mas por causa do valor intrínseco do objeto. Desinteresse, portanto, não é um aspecto psicológico - ele não caracteriza o estado no qual a intencionalidade do juízo moral ou estético é saturado com prazer (se assim posso dizer). Ao contrário, ele é o principal, o aspecto lógico, do conhecimento daquilo que tem valor intrínseco. Aqui, conhecimento não é "conhecimento do uso", é exatamente o oposto. Cito o Ensaio sobre a Liberdade de Wit e Humor, I: "Se a virtude não for realmente estimável em si mesma, não consigo ver nada estimável em segui-la pelo bem de um negócio. Se o amor por fazer o bem não for, propriamente, uma inclinação boa e certa, não sei como possa haver, talvez, tal coisa como Bondade e Virtude. Se a inclinação estiver certa, é uma perversão aplicá-la somente à gratificação, e nos fazer conceber tais maravilhas da graça e do favor, que devem dizer respeito à virtude, quando muito pouco do mérito ou valor da própria coisa está exposto." Nosso juízo naquele caso é desinteressado porque consiste no co-

2 Shaftesbury, "Characteristicks of Men, Manners, Opinions, Times", editado por Douglas den Uyl. Indianapolis: Liberty Fund, 2001, vol. I, pp. 61-62. 
nhecimento do que é "estimável em si mesmo". Aqui o objeto intencional do juízo não é o prazer, mas a própria coisa. ${ }^{3}$

Portanto, podemos inferir que quando Hutcheson afirma provar "a realidade da virtude" (Ibid., Prefácio, p. 8), o que ele tem em mente é muito diferente do realismo platônico ou estoico que Shaftesbury quis promover. A beleza hutchesoniana não pode ser real em sentido forte, isso é, não pode existir independentemente de ser percebida, pois Hutcheson enfatiza que "por beleza absoluta ou original não se entende qualquer qualidade que se supõe estar no objeto, o qual deveria ser por si mesmo belo, sem relação a qualquer mente que o perceba, pois beleza, como outros nomes de ideias sensíveis, denota propriamente a percepção de alguma mente" (p. 27-28) 4. Não vejo porque isso também não deveria ser verdade para bondade. Pode-se argumentar que, para Hutcheson, as propriedades que são apreendidas pelo sentido de beleza natural, bem como aquelas apreendidas pelo sentido moral, são qualidades reais nos objetos. Claro que são qualidades reais, mas o tipo de realidade que têm é aquele de uma causa de fundo que opera no perceptor sem ser conhecida por ele (aqui reconhecemos o

3 Não sigo J. Stolniz: "a explicação de Hutcheson sobre desinteresse, na maioria dos casos, simplesmente repete a de Shaftesbury... em apenas um caso a análise de Hutcheson é significativamente diferente. Ele exclui da estética qualquer referência ao conhecimento do objeto. Tal conhecimento pode ser bem-vindo "a partir da perspectiva de vantagem" e pode despertar prazer intelectual ou cognitivo. Ainda que seja totalmente diferente da fruição de beleza e não possa ter nenhum efeito sobre a experiência. Isso, mais uma vez, é apenas um desenvolvimento da compreensão de Shaftesbury de que o interesse estético está exclusivamente na percepção e se limita ao próprio objeto". "On the origins of 'Aesthetic Disinterestedness', The journal of aesthetics and art criticism, vol. 20, No. 2. (Winter, 1961), p. 134. Para uma crítica do amplo uso de Stolniz do conceito de desinteresse, veja R. Miles, "The Concept of Disinterestedness in Eighteenth-century British Aesthetics", Journal of the history of philosophy, 40, 1 (2002), pp. 67-87.

4 Concordo com Richard Glauser: "Contrariamente a Hutcheson e Hume, contudo, Shaftesbury geralmente defende um conceito realista de beleza. Hutcheson separa, de um lado, a beleza, e, de outro, a fundação ou causa objetiva, nas próprias coisas, de nossa apreciação de sua aparência bela. Para Hutcheson a beleza é uma mera ideia, relativa - embora comum - às mentes de toda humanidade". R. Glauser, "Aesthetic Experience in Shaftesbury", Proceedings of the Aristotelian Society, Supplementary Volumes, 76, pp. $25-54$ (p. 27). 
conceito lockeano de poder causal, e o agnosticismo ontológico que o acompanha), e isso é muito diferente da realidade que Shaftesbury atribui ao objeto de juízos de valor.

A conclusão dessa primeira parte de minha argumentação é a de que Shaftesbury e Hutcheson não compartilham o mesmo conceito de juízo moral ou juízo estético, mesmo se nos concentrarmos naquilo que eles supostamente concordam, ou seja, que graças ao sentido interno somos capazes de uma apreciação imediata e desinteressada de valores. Agora, vou para meu segundo ponto.

\section{Qual analogia entre o bom e o belo?}

No seu prefácio, Hutcheson formula, muito claramente, a relação lógica (e também retórica) entre o argumento sobre o sentido de beleza no primeiro tratado e o argumento sobre o sentido moral no segundo tratado. O primeiro tratado é uma preparação epistemológica para o segundo, como fica muito claro na seguinte passagem: "Se o leitor estiver convencido de tais determinações da mente para se satisfazer com formas, proporções, semelhanças, teoremas, não será uma questão difícil apreender um outro sentido superior, também natural aos homens, determinando-lhes que se satisfaçam com ações, caracteres, afecções. (Ibid. p.86) “A ligação entre o argumento sobre o sentido de beleza e o argumento sobre o sentido moral não implica absolutamente a pretensão de que haja mais do que uma mera analogia entre os processos psicológicos que operam no sentido de beleza e os processos psicológicos envolvidos no sentido moral.

Logo no início da seção 1 do tratado II, Hutcheson afirma que “as percepções de bem e mal morais são perfeitamente diferentes daqueles de bem natural ou vantagem (Ibid., p. 89). Algumas linhas abaixo, ele associa intimamente o conceito de "vantagem ou interesse que surge dos sentidos externos" ao de "percepções de beleza e harmonia", de modo que devesse ficar bastante claro 
para o leitor que “as percepções de bem e mal morais” são também “perfeitamente diferentes” das percepções de beleza natural e harmonia. Até onde sei Hutcheson nunca une "beleza natural” com "beleza moral”. Entretanto, ele não diz que "beleza moral” nada tem a ver com "beleza natural”, uma vez que tal tese seria errada em alguns casos (não em todos os casos): pois é óbvio que em casos os quais Hutcheson chama de "beleza relativa" (ou seja, beleza imitativa, expressiva, simbólica ou mais geralmente representativa), em oposição a "beleza absoluta”, a beleza natural é um modo de transmitir beleza moral. É somente em casos de beleza relativa que existe uma forte conexão entre beleza natural e beleza moral. Por exemplo, o retrato de Hércules pode expressar sua coragem. Se colocarmos de lado a beleza relativa e focarmos na beleza absoluta, então não são apenas beleza moral e beleza natural perfeitamente diferentes, mas não existe em absoluto qualquer conexão entre elas. Em particular, não podemos dizer que beleza absoluta simboliza ou expressa bondade moral. Se existe qualquer analogia entre bondade (ou beleza moral) e beleza (natural), ela não é uma analogia entre formas belas e formas morais, mas uma analogia entre disposições psicológicas, isto é, entre o sentido (não moral) de beleza e o sentido (moral) de bem. Quando Hutcheson fala sobre o "sentido moral de beleza em ações" (Ibid., p. 140), a analogia não é entre beleza em ações e beleza natural (isto é, estética), mas antes entre os diferentes processos psicológicos através dos quais o bom e o belo são apreendidos.

A razão para isso é que Hutcheson subscreve a uma versão bastante radical da tese de heterogeneidade, de acordo com a qual, cito o início do primeiro tratado, "quando duas percepções são totalmente diferentes entre si, ou só têm correspondência na ideia geral de sensação, chamamos sentidos diferentes os poderes de receber essas diferentes percepções" (Ibid., p. 19). Nessa passagem, Hutcheson está lidando com sentidos externos, todavia não vejo qualquer razão porque essa tese não deveria também dirigir-se a sentidos internos. Se houver algum acordo entre duas per- 
cepções além do fato de que ambas sejam percepções, por exemplos se ambas forem não apenas percepções, mas percepções de cor, então elas pertencem ao mesmo sentido, nesse caso ao sentido da visão. Se tomarmos essa afirmação por verdadeira, então sua contrapositiva é verdadeira também: quando duas percepções não pertencem ao mesmo sentido, então não existe qualquer acordo entre elas além do fato de que ambas sejam percepções. Ora, de acordo com Hutcheson a percepção do bem não pertence ao mesmo sentido que a percepção do belo. Portanto, não existe nada em comum entre a percepção do bem e a percepção do belo além do fato de que sejam percepções.

Claro que esse argumento não descarta a possibilidade de que a mesma qualidade causaria ambas as percepções. Podemos imaginar que uma qualidade desconhecida dê origem a duas percepções que pertencem a sentidos diferentes. Não haveria qualquer contradição entre a tese de heterogeneidade e aquela afirmação, visto que a tese de heterogeneidade é sobre as percepções como efeitos de poderes ou qualidades, não sobre os próprios poderes ou qualidades. Poderíamos ter dois efeitos heterogêneos para a mesma causa. Entretanto, até onde sei, Hutcheson não explora essa possibilidade. A razão talvez seja que a explicação de Hutcheson é fenomenológica e, como tal, não está interessada na questão, já que a existência daquela causa comum não seria refletida em absoluto em nossas percepções. É significativo que Hutcheson não tenha tentado confiar a uma qualidade comum a tarefa de preencher a lacuna entre beleza natural e beleza moral.

Vamos nos voltar agora para Shaftesbury. De acordo com ele, o juízo pelo qual atribuímos beleza a um objeto pode ser verdadeiro ou falso, dependendo se o objeto é realmente belo ou não. O critério para beleza real é a bondade moral. Pois o que é moralmente bom é também belo de duas maneiras: 1. Diretamente: por exemplo, a virtude de Hércules, como uma disposição moral, é intrínseca e diretamente belo. 2. Indiretamente: o corpo de Hércules é indiretamente belo, na medida em que expressa 
disposições morais de Hércules. Também, um retrato de Hércules é indiretamente belo. Em resumo, toda beleza real tem seu fundamento, direta ou indiretamente, em moralidade. Quando a conexão é indireta, isto é, quando beleza expressa ou exterioriza moralidade nas formas de arte e ou de natureza, então lidamos com o que podemos chamar de a moralidade da beleza. No caso da beleza de moralidade, é o próprio bem que é belo. No caso da moralidade de beleza, é a forma expressiva que é bela na medida em que simboliza o bem. Em ambos os casos, o bem é o fundamento do (realmente) belo. Claro, a maioria de nós não usa o bem como critério para o belo. Ficamos felizes com belezas que não estão nem direta nem indiretamente fundadas na moralidade. Para o platonista, para o estoico também, tal juízo não é apenas superficial, mas também falso. Aqui vou me valer das Miscelâneas, Miscelânea IV, capítulo I, na qual Shaftesbury resume sua filosofia moral e retrata a si mesmo como um discípulo de Sócrates e dos estoicos:

"Eu observo em mim que tenho a imaginação de algo belo, grande, e devir de coisas. Essa imaginação eu aplico talvez a objetos tais como prataria, joias, apartamentos, grinaldas, patentes de honra, títulos ou precedências. Devo, portanto, naturalmente procurá-los, não como simples conveniências, meios ou auxílios na vida (pois, como tal, minha paixão não poderia ser tão excessiva em direção a eles), mas como excelentes em si mesmos, que atraem necessariamente minha admiração, e que, direta e imediatamente, causam minha felicidade e me dão satisfação. Ora, se a paixão suscitada nessa opinião (chame-a de avareza, orgulho, vaidade ou ambição) for realmente incapaz de qualquer satisfação real, mesmo sob o mais bem sucedido curso do destino; e assim também, ocupada com medos perpétuos de desapontamento e perda: como a mente pode estar senão que miserável, quando possuída por isso? Porém, se ao invés de formarmos nesse caso a opinião de bem; se ao invés de atribuirmos valor ou excelência a esses objetos externos, atribuíssemo-lo, onde mais verdadeiro, a 
afetos e sentimentos, à parte governante e caráter interior; tê-lo-íamos, então, em pleno gozo e em nosso poder: a imaginação ou opinião permanece firme e irreversível, e o amor, desejo e apetite são respondidos, sem apreensão de perda ou desapontamento" (Shafstebury, 2001, vol. 3, p. 120-121).

Aqui a argumentação de Shaftesbury claramente pressupõe duas proposições que não encontramos em Hutcheson. Primeiramente, que o juízo estético tem um valor real porque tem um conteúdo cognitivo. Em segundo lugar, que o conteúdo cognitivo no caso da beleza interna (a beleza de moralidade) é idêntico ao conteúdo cognitivo do juízo moral correspondente; no caso da beleza externa, o conteúdo cognitivo implica, como sua condição, um juízo moral correspondente. Por exemplo, acho (erroneamente) que "objetos tais como prataria, joias, apartamentos, grinaldas, patentes de honra, títulos ou precedências" são belos porque julgo (erroneamente) que são "excelentes em si mesmos". Resumindo, Shaftesbury dá uma explicação racionalista de juízos estéticos e morais, de acordo com a qual eles não apenas expressam nossas preferências subjetivas, mas também consistem na crença, verdadeira ou falsa, que seus objetos tenham certas propriedades. Além disso, Shaftesbury não restringe o alcance da analogia entre o bom e o belo. Ao contrário, sugere que haja uma conexão necessária entre juízos estéticos e juízos morais e que a conexão é baseada na identidade entre o belo e o bem no caso da beleza de moralidade, ou ao menos na expressão de bem pelo belo no caso de moralidade de beleza, como aparece nesta passagem da terceira Miscelânea, capítulo 2: “'O que é belo é harmonioso e proporcional; o que é harmonioso e proporcional é verdadeiro; e o que é de uma só vez tanto belo como verdadeiro é, por consequência, agradável e bom?' Onde, então, essa beleza e harmonia deve ser encontrada? Como essa simetria deve ser descoberta e aplicada? Há alguma outra arte senão a de filosofia, ou o estudo dos números e proporções internos, que possa exibir isso na vida? Se nenhuma outra; quem, então, pode possivelmen- 
te ter um gosto desse tipo, sem estar em dívida com a filosofia? Quem pode admirar as belezas externas e não ser referido instantaneamente às internas, que são as mais reais e essenciais, as mais naturalmente comoventes, e de mais elevado prazer, bem como lucro e vantagem?" (Miscellaneous Reflections, vol. III, p. 111-114). Para aquele que foi treinado na filosofia, aquele cujo gosto foi cultivado, a beleza externa aponta para a beleza interna, ou seja, a beleza da mente e suas afecções ou disposições. Essa forte conexão entre beleza interna e beleza externa é muito importante para entender a escala platônica de belezas que encontramos em muitas passagens e especialmente em Os Moralistas, Uma Rapsódia Filosófica. Não desenvolverei esse ponto aqui. É suficiente para minha argumentação notar que Shaftesbury profundamente identifica o belo com o bom. Ora, lembremos que a distinção hutchesoniana entre dois sentidos, um para a percepção de beleza e outro para a percepção de bem moral, é um modo breve de provar que Hutcheson tem como premissa a impossibilidade de identificar o belo com o bom.

Não direi que o encômio de Hutcheson a Shaftesbury baseia-se em uma má compreensão no sentido de que Hutcheson não teria conhecimento de que sua epistemologia lockeana era muito diferente do realismo socrático o qual Shaftesbury sustenta. Valendo-se de Locke para defender a realidade da virtude contra Mandeville foi um feito marcante do qual Hutcheson estava bem consciente. Ele não poderia ter ignorado o fato de que Saftesbury ao lado dos platonistas de Cambridge, não ao lado de Locke. Se o encômio de Hutcheson a seu defensor não se apoia em uma má compreensão, uma vez que seus pontos de vista são tão profundamente opostos, podemos ficar tentados a concluir que o elogio não seja sincero. Essa conclusão não seria justa. Devemos, antes, prestar atenção ao fato de que, mesmo que seus argumentos para desinteresse sejam baseados em premissas diferentes, Hutcheson congratula Shaftesbury por um tópico preciso, ou seja, por sua demonstração de que a apreciação moral não pode ser reduzi- 
da à expressão de interesse próprio. Desse modo, deveríamos não apenas concluir que seus princípios metaéticos eram diferentes, mas também que suas considerações metaéticas sobre a natureza do juízo moral e das propriedades morais etc. foram menos importantes para Shaftesbury e Hutcheson do que sua proposição substantiva comum sobre o significado de desinteresse. ${ }^{5}$

\section{Bibliografia}

GLAUSER, R. "Aesthetic experience in Shafstebury", Proceedings of the Aristotelian Society, Supplementary Volumes, 76, pp. 25-54.

HUTCHESON, F. An inquiry into the original of our ideas of beauty and virtue, in two treatites. Ed. W. Leidhold, Indianapolis, Liberty Fund, 2004.

MILES, R. "The concept of desinterastedness in eighteenth century british aesthetics", Journal of History and Philosophy, 40 (1), 2002.

SHAFSTEBURY, Characteristics of men, manners, opinions, times, Ed. D. Uyl, Indianapolis, Liberty Fund, 2001, 3 vols.

STOLNITZ, J. "On the origins of aesthetis and criticism", vol. $20, \mathrm{n}^{\circ} 2$ $(1961)$.

5 Esta pesquisa foi conduzida com o apoio do Capes-Cofecub (SH 754-12). 


\title{
Francis Hutcheson, da beleza à perspectiva do desígnio
}

\author{
Lisa Broussois
}

Paris I Panthéon-Sorbonne

Tadução: Leonardo Paes Müller 

This Beauty arising from Correspondence to Intention, would open to curious Observers a new Scene of Beauty in the works of NATURE, by considering how the Mechanism of the various Parts known to us seems adapted to the Perfection of that Part, and yet in Subordination to the Good of some System or Whole. ${ }^{1}$

Francis Hutcheson (1725/26, p. 40)

\section{Introdução: Investigação sobre as nossas ideias da beleza e da virtude}

Francis Hutcheson publicou em 1725 sua Investigação sobre as nossas ideias da beleza e da virtude. Essa obra é composta por dois tratados, nos quais, segundo o próprio subtítulo da obra, ele defende e explica os princípios de Lord Shaftesbury contra o autor da Fábula das Abelhas, Bernard Mandeville. O primeiro tratado apresenta a tese da existência de um senso de beleza nos seres humanos. É a parte da Investigação destinada à "beleza, ordem, harmonia e desígnio". O segundo tratado desenvolve sua teoria a respeito da existência de um senso moral e se intitula "Investigação sobre a origem de nossas ideias do bem e do mal morais". No

1 Ver nota 19, abaixo. As edições da Investigação de Francis Hutcheson utilizadas foram as seguintes: Hutcheson, Recherche sur l'origine de nos idées de la beauté et de la vertu. Anne-Dominique Balmès (traduction française). Paris: Vrin, 1991 e em inglês: Hutcheson, An inquiry into the original of our ideas of beauty and virtue; Alterations and additions made in the second edition ot the "Inquiry into beauty and virtue". Londres: J. Darby, for W. and J. Smith, 1725/1726; Hutcheson, An essay on the nature and conduct of the passions and affections (Ensaio sobre a natureza e a conduta das paixões e afecções). Londres: J. Darby and T. Browne, for J. Smith and W. Bruce, 1728 e Hutcheson, A Short Introduction to Moral Philosophy (Curta introdução à filosofia moral). Glasgow: R. Foulis, 1747. O título completo da primeira edição da Investigação é: An Inquiry into the Original of our Ideas of Beauty and Virtue; in Two Treatises in which The Principles of the Late Earl of Shaftesbury are Explain'd and Defended, against the Author of the Fable of the Bees: and the Ideas of Moral Good and Evil are establish'd, according to the Sentiments of the Ancient Moralists. With an Attempt to introduce a Mathematical Calculation in Subjects of Morality. Ou seja: "Investigação sobre a origem de nossas ideias de beleza e virtude em dois tratados, nos quais são explicados e defendidos os princípios do falecido Conde de Shafesbury contra o autor da Fábula das abelhas, e as ideias de bem e mal morais são definidas de acordo com os sentimentos dos moralistas antigos. Com uma tentativa de introduzir um cálculo matemático em objetos morais" (Hutcheson, 1991, p. 8-9). 